\title{
Follow the leader: How expert ratings mediate consumer assessments of hedonic quality
}

\author{
D. Priilaid*, J. Feinberg, O. Carter and G. Ross \\ School of Management Studies, University of Cape Town, \\ Private Bag, Rondebosch 7700, Republic of South Africa \\ david.priilaid@uct.ac.za
}

Received June 2009

\begin{abstract}
Within the context of sighted wine appreciation, previous studies indicate that extrinsic cues like price and area-of-origin have a marked effect on the sighted ratings proffered by tasting experts. While these expert ratings are widely employed by the wine media as proxies of genuine quality, it remains uncertain whether such expert ratings, in turn, serve to influence the public in their own sighted assessments of wine quality. To determine the influence of the expert rating cue in the public's sighted appreciation of wine, a tasting-room experiment was held in which 32 subjects assessed seven wines first blind and then sighted. During the sighted tasting the only (additional) cue-information made available was the expert rating conferred by the South African annual wine-guide known as John Platter. An interrogation of the resultant database of 224 paired blind and sighted wine assessments reveals the extent to which the expert rating cue consistently mediates the sighted appreciation of wine, this particularly within the younger, less experienced demographic. An examination of the meta-model's driving coefficients suggests that in explaining sighted quality, expert ratings appear to operate at five times the strength of the original intrinsic (blind) assessment. For marketers, this finding suggests (1) that the promotion of this extrinsic cue be targeted more specifically at wine "novices", and (2) that this narrowing of marketing focus implies a more judicious and effective employment of media budgets.
\end{abstract}

*To whom all correspondence should be addressed.

\section{Introduction}

In the retailing of sensory commodities like wine, extrinsic cues are deemed critically important, since they enable the increase of hedonic enjoyment without additional cost or effort in either cellar or vineyard. Studies have shown that the wine-buying public employ these cues as their predominant criteria of appraisal (Spawton, 1991). This is most especially the case since wine consumers are renowned for high levels of product uncertainty, and thus generally formulate decisions-to-purchase only when in store (Seghieri, Casini \& Torrisi, 2007). Two such cues are identified in the literature as mediators of a wine's intrinsic (underlying) merit; namely price (Plassmann, O’Doherty, Shiv, \& Rangel, 2008) and area-of-origin/terroir (Priilaid, 2007). In this study we identify and explore expert ratings as a potential third mediator. To proceed, we observe that by convention a wine's intrinsic merit is best assessed when tasted blind; with the mediating effect of any extrinsic cues captured in a sighted assessment and defined as a placebo (see Shiv, Carmon \& Ariely, 2005).

Using these definitional constructs, we report on a tastingroom experiment in which 32 subjects assessed seven merlot wines first blind and then sighted. In both tastings the cultivar was made known to the subjects; the sequence of sighted tasting, however, differed from that of the blind tasting. During the second tasting the only (additional) cueinformation made available was the expert rating conferred by the annual wine guide known as John Platter. (By specification, we term this second round the "sighted tasting" in that it contrasts with the completely blind tasting of Round One.) It was the influence of the expert Platter cue that this study sought to investigate.

Collating the scores of each participant, a database of 224 paired blind and sighted wine assessments (as manifest in star ratings) was constructed and then interrogated so as to observe the extent to which expert ratings influence sighted appreciation whilst controlling for intrinsic merit. With the brand, price and area-of-origin all undisclosed, no further cue-controls were required.

As with previous studies on wine's placebo effect, it is this paper's contention that in the sighted assessment of wine, prevailing cue-effects are likely to demean or obscure the import of intrinsic merit. In this instance we seek, in particular, to know whether expert ratings serve also as such a cue, and if so, to what extent. The contribution of this paper is therefore unique in that for the first time, blind and sighted tasting results are collated and statistically interrogated for evidence of this particular cue-effect.

The following section reviews the relevant literature. Section 3 presents the design of the outlined experiment and describes the dataset developed. The empirical findings of the experiment appear in Section 4. A discussion on the implications concludes the paper. 


\section{Literature review}

The term placebo is defined as "an inactive substance that is used in controlled studies to determine the effectiveness of medications" (Borsook \& Becerra, 2005: 394). Beyond the science of medicine, though, the placebo presents by way of some form of extrinsic cue, serving neurologically as a riskreducing heuristic (see Montague, 2006) that can modulate the efficacy of certain hedonic products. At the point of purchase or other such places where the merit assessment of a product like wine is unlikely, extrinsic cues become enabling clues in the decision-making process (Thrane, 2004). In the light of these insights, recent studies have begun to focus on the nature and extent to which extrinsic cues operate in the wine market, inter-alia. In separate studies, the efficacy of two placebo-like cues has been presented: price and area-of-origin/terroir.

The first works to consider the price cue as an important (though) unconscious mediator of experienced pleasure appeared in a specially published edition of the Journal of Marketing Research focussing solely on the placebo effect (see Rao, 2005; Berns, 2005; Borsook \& Becerra, 2005; Irmak, Block \& Fitzsimons, 2005; and, principally, Shiv et al., 2005). More recently, Plassmann and colleagues used functional Magnetic Resonance Imaging (fMRI) scanning techniques to observe the neurological response of twenty subjects to changes in wine price whilst holding quality constant. The results confirmed the expectations of previous studies: "increasing the price of a wine increases subjective reports of flavour pleasantness as well as blood-oxygenlevel-dependent activity in the medial-orbitofrontal cortex, an area widely thought to encode for experienced pleasantness during experimental tasks" (Plassmann et al., 2008: 1050).

In a further placebo-related wine study Priilaid (2007) sought to codify ward-contingent terroir-effects in the hedonic quality of wines emanating from certain areas. Inter-alia, this paper (1) illustrated the extent to which blind and sight-based versions of hedonic quality rendered different permutations of terroir effects; and (2) established that while the sighted versions reveal a richer and more detailed calibration of terroir, blind versions are generally impaired by a muted level of statistical significance and ward differentiation. In conclusion, the paper observed, as with previous studies, that the sighted approach appears neurologically flawed because of a prior knowledge of the extrinsic cues at hand.

The present study moves on to present professional scores as a third potential wine-based placebo-effect. Citing the influence of wine tasting professionals like Robert Parker, Priilaid and Van Rensburg (2006) have argued that professional ratings guide wine-purchasing behaviour. While in the best sense expert ratings can demystify elitist jargon for consumers, less positively they have received criticism for converting consumers into mindless puppets whose buying behaviours merely mimic the aesthetic mores of local wine experts (Darlington, 2005). Pursuing this argument, Priilaid (2007) implied that the consumer's slavish abeyance to such ratings granted the quality assessors unique powers to confer rulings on matters that were, historically, beyond their jurisdiction. By adjudicating on issues of hedonic quality, terroir, and the like, the locus of wine-power appeared thus to have shifted from an area of technical producer-based expertise to one where the expert assessors (in many instances selfproclaimed) now held sway. The tail, he concluded, had now started to wag the dog.

In the light of prevailing market realities, this situation appears quite understandable: few regular customers can claim to have the money, time, expertise or capacity to test the merit of all wines available at any particular time and so make a properly informed choice. More so, when the risk of an inappropriate wine choice may reflect negatively on the one who selected it, an apparently straightforward selection can potentially evoke some social embarrassment. Perhaps understandably therefore, a good number of wine drinkers who care about the quality of their purchases consequently employ expert ratings as risk-reducing heuristics to guide their buying and consumption behaviour.

In South Africa, one of the better-known professional ratings employed as bottle stickers is Platter's South African Wine Guide. This is a well-known, respected and highly sought-after taste-guide-publication that provides the ratings of all South African wines on an annual basis. Informally christened after its founding editor, (John) Platter's Guide was first published in 1981 and scores off the five-star or twenty-point scoring system. All the tastings are conducted sighted. Wines scoring over 18 points receive the superlative five-star award. Wines scoring between 16 and 17 points are considered excellent and receive four stars. A three-star or 15-point wine is deemed good to very good, while appealing wines receive 14 points or a two-star rating. Average wines score 13 points; equivalent to a one-star rating. Unacceptable wines receive zero stars.

Between June and August each year, Platter's taste-team assesses roughly 6000 wines. These are apportioned equally across the approximately ten-member tasting-panel and all wines are tasted individually on a farm-to-farm basis. By December each year, following a comprehensive editorial process, the annual Platter is released to the bookshops. Platter is one of the most widely enjoyed publications in South Africa - with over 60000 volumes printed each year. Not only is it also published on the internet (see platterwineguide.co.za), it has been acclaimed internationally, receiving (inter-alia) the 2007 Louis Roeder International Wine Writers' Award. More than this, it has also formed the basis of several internationally-published wine studies (see for example Priilaid \& Van Rensburg, 2006 and Priilaid, 2007). Writing recently in her column for the Financial Times, Jancis Robinson (2008: 4) commented: "I can think of no other country that has a single annual, comprehensive and definitive guide to wines produced there". Reflecting on the guide's influence on consumer behaviour, local wine expert Michael Fridjhon (pers. comm., 2008) noted how frequently four-and-a-half and five-star wines have sold out from all retailers. Hermann Kirschbaum, winemaker at the Buitenverwachting wine estate (pers. comm., 2008) stated that Platter was seen to influence purchase decisions since potential customers on the estate would first consult the guide before participating in a wine tasting, and then only taste those wines deemed worthwhile by Platter. When armed with a Platter, he 
noted, consumers do not appear to form their own opinions, buying merely what is in the book. Boycotting a publication as powerful and popular as Platter, he concluded, was therefore not an option since it would impair their wine sales.

In the light of these considerations, it is worth considering whether Platter's expert ratings also serve as placebo-like extrinsic cues that, like price and area-of-origin, serve to mask the intrinsic merit of a wine.

\section{Experimental design and data description}

To investigate the effect of expert ratings on the assessment of intrinsic merit, a quasi-experimental design was employed (see Malhotra, 2007) in which we invited 32 subjects (21 males; 11 females) to participate in a two-stage wine-tasting. By way of a self-administered questionnaire, respondents were requested to provide information regarding their age, gender, the length of time they had been drinking (in years), and their weekly wine consumption. Using a five-point likert scale (with one denoting "novice", to five denoting "expert"), they were also asked to rate their relative level of expertise in the local wine market.

At the start of the tasting subjects were informed that the varietal to be tasted would be merlot. By virtue of its popularity both locally and overseas, merlot was deemed a varietal with which all participants would be familiar. Globally, merlot is the most prolifically planted red varietal, and constitutes $6,83 \%$ of the South African vineyard. By this measure, it is the third most popular South African red cultivar after cabernet sauvignon (18,75\%) and shiraz (9,64\%) (see Boom, 2006: 392-3). While other cultivars also presented themselves as potential candidates, by virtue of the factors noted above, merlot was thus deemed sufficiently suitable for this study.

Tasting was scored using the previously described five-star system. In Round One, participants assessed eight wines blind (apart from knowledge of the varietal). In Round Two the same exercise was repeated, but this time with seven wines in a different sequence (and not eight as previously.) By dropping a wine in Round Two and re-shuffling the tasting sequence we sought to discourage participants from picking out patterns in the tasting line-up and guessing accordingly. Critically, in Round Two, the expert Platter score of each wine was made known; hence its "sighted" specification. A list of the seven wines tasted blind and sighted appears in Table I. Apart from the expert-rating cue, no additional information was made available during the second tasting. (The varietal cue was made known in both rounds.)

Table 1: The seven wines tasted by all 32 subjects.

\begin{tabular}{c|c|c}
\hline Estate & Vintage & Platter Rating \\
\hline Thelema Mountain Vineyards & 2006 & 4 \\
\hline Vergelegen & 2005 & 3,5 \\
\hline Villiera & 2005 & 3 \\
\hline Spier Reserve & 2005 & 4 \\
\hline Bilton & 2004 & 4,5 \\
\hline Rust en Vrede & 2005 & 4 \\
\hline Guardian Peak & 2006 & 3,5 \\
\hline
\end{tabular}

By integrating information from the 32 self-administered questionnaires and the seven wines scored blind and sighted by each participant, a dataset of 224 wine assessments was compiled. The 224 sample size compares well with a similar experimental study conducted by Plassmann et al. (2008) which employed 20 subjects tasting five wines and a neutral solution. Descriptive statistics pertaining to the dataset appear in Table II below. Through the control of the intrinsic merit scores as measured in Round One, we explored this dataset to determine the impact of expert ratings on sighted scores.

\section{Methodology and model construction}

In Table III the (Spearman) correlation matrix of sighted quality and the various candidate variables is presented. The correlation between blind and sighted ratings is weak and positive $(0,16)$. Such correlative weakness suggests that secondary factors might be driving the sighted appreciation of the sampled wines; a view confirmed when we observe the variable most strongly correlated with the sighted score, which, as we conjectured, is the expert Platter score (correlation $=0,25$ ). In line with expectations, high degrees of positive inter-correlation are noted between age, years of drinking, drinks per week and knowledge of the wine industry. The correlations between these variables and the sighted tasting, however, are not strong. After Platter and the blind score, the variables "age" and "years of drinking" present with the strongest correlations (- 0,14 and 0,13 , respectively). 
Table 2: Descriptive statistics. Note: of the 32 subjects: males $=21$, females $=11$.

\begin{tabular}{|c|c|c|c|c|c|c|c|}
\hline & $\begin{array}{l}\text { Age of } \\
\text { subject }\end{array}$ & $\begin{array}{l}\text { Years of } \\
\text { drinking }\end{array}$ & $\begin{array}{c}\text { Drinks } \\
\text { per week }\end{array}$ & $\begin{array}{l}\text { Knowledge } \\
\text { of industry }\end{array}$ & $\begin{array}{c}\text { “Expert” } \\
\text { Platter } \\
\text { Score }\end{array}$ & $\begin{array}{l}\text { Blind } \\
\text { tasting }\end{array}$ & $\begin{array}{c}\text { Sighted } \\
\text { tasting }\end{array}$ \\
\hline Minimum & 18 & 1 & 0,25 & 1 & 3 & 0 & 1 \\
\hline Maximum & 63 & 45 & 7 & 5 & 4,5 & 5 & 5 \\
\hline Median & 24 & 8 & 1 & 2,5 & 4 & 3 & 3 \\
\hline Mode & 21 & 8 & 1 & 3 & 4 & 3 & 3 \\
\hline Mean average & 27,69 & 11,58 & 2,34 & 2,56 & 3,79 & 2,71 & 3,21 \\
\hline Std. Deviation. & 11,17 & 11,60 & 2,16 & 1,15 & 0,45 & 1,10 & 0,87 \\
\hline Range & 45 & 44 & 6,75 & 4 & 1,5 & 5 & 4 \\
\hline Kurtosis & 2,91 & 2,67 & 0,37 & $-0,21$ & $-0,72$ & $-0,55$ & $-0,48$ \\
\hline Skewness & 2,03 & 1,96 & 1,37 & 0,54 & $-0,21$ & $-0,03$ & $-0,03$ \\
\hline $\mathbf{n}$ & 32 & 32 & 32 & 32 & 7 & 224 & 224 \\
\hline
\end{tabular}

Table 3: A Spearman's rank correlation matrix depicting variables across the entire dataset $(\mathbf{n}=224)$

\begin{tabular}{|c|c|c|c|c|c|c|c|c|}
\hline & & $\begin{array}{l}\text { Sighted } \\
\text { tasting }\end{array}$ & $\begin{array}{l}\text { Blind } \\
\text { tasting }\end{array}$ & $\begin{array}{l}\text { Platter } \\
\text { rating }\end{array}$ & $\begin{array}{l}\text { Years of } \\
\text { drinking }\end{array}$ & $\begin{array}{c}\text { Drinks } \\
\text { per week }\end{array}$ & Age & $\begin{array}{c}\text { Knowledge } \\
\text { of wine } \\
\text { industry }\end{array}$ \\
\hline Sighted tasting & $\begin{array}{l}\text { Correlation } \\
\text { Coefficient }\end{array}$ & 1 & & & & & & \\
\hline \multirow[t]{2}{*}{ Blind tasting } & $\begin{array}{l}\text { Correlation } \\
\text { Coefficient }\end{array}$ &, $16(*)$ & \multirow[t]{2}{*}{1} & & & & & \\
\hline & Sig. (2-tailed) & 0,02 & & & & & & \\
\hline \multirow[t]{2}{*}{ Platter rating } & $\begin{array}{l}\text { Correlation } \\
\text { Coefficient } \\
\end{array}$ &, $25(* *)$ & 0,13 & \multirow[t]{2}{*}{1} & & & & \\
\hline & Sig. (2-tailed) & 0,00 & 0,05 & & & & & \\
\hline \multirow{2}{*}{$\begin{array}{c}\text { Years of } \\
\text { Drinking }\end{array}$} & $\begin{array}{l}\text { Correlation } \\
\text { Coefficient } \\
\end{array}$ &,$- 13(*)$ & 0,07 & 0,00 & \multirow[t]{2}{*}{1} & & & \\
\hline & Sig. (2-tailed) & 0,05 & 0,32 & 1,00 & & & & \\
\hline \multirow{2}{*}{$\begin{array}{c}\text { Drinks } \\
\text { per week }\end{array}$} & $\begin{array}{l}\text { Correlation } \\
\text { Coefficient }\end{array}$ & $-0,09$ &, $15(*)$ & 0,00 &, $56(* *)$ & \multirow[t]{2}{*}{1} & & \\
\hline & Sig. (2-tailed) & 0,17 & 0,03 & 1,00 & 0,00 & & & \\
\hline \multirow[t]{2}{*}{ Age } & $\begin{array}{l}\text { Correlation } \\
\text { Coefficient }\end{array}$ &,$- 14(*)$ & 0,05 & 0,00 &, $79(* *)$ &, $46(* *)$ & \multirow[t]{2}{*}{1} & \\
\hline & Sig. (2-tailed) & 0,03 & 0,44 & 1,00 & 0,00 & 0,00 & & \\
\hline \multirow{2}{*}{$\begin{array}{l}\text { Knowledge of } \\
\text { wine industry }\end{array}$} & $\begin{array}{l}\text { Correlation } \\
\text { Coefficient }\end{array}$ & $-0,05$ & 0,11 & 0,00 &, $32(* *)$ &, $69(* *)$ &, $42(* *)$ & \multirow{2}{*}{1} \\
\hline & Sig. (2-tailed) & 0,45 & 0,12 & 1,00 & 0,00 & 0,00 & 0,00 & \\
\hline
\end{tabular}

* Correlation is significant at the 0,05 level (2-tailed) ** Correlation is significant at the 0,01 level (2-tailed)

Due to the make-up of the data on hand, an analysis of variance (ANOVA) methodology is merged with the Gaussian ordinary least squares (OLS) technique thereby allowing for the conversion of certain explanatory variables into dichotomous or "dummy" variables. Thus each of the variables "age", "gender", "years of drinking wine", "drinks per week" and "knowledge of the wine industry" is spliced and dummy coded into non-linear categorical variables. Age is decomposed into five categorical variables: "18-21", "22-25", "26-30", "31-35" and "Over 35". Similarly the variable "Years of drinking wine" is coded into three time bands: "zero to eight years", "9-35 years" and "over 35 years". Three categorical variables cover "drinks per week": "one or less", "two to four" and "five or more". Finally we disaggregate the "Knowledge of the wine industry" variable into three categorical variables: "one to two" (novice), "three" (intermediate), and "four to five" (expert). Methodologically analogous studies of the South African wine industry (see Priilaid, 2007) and tertiary academic institutions (see Van Rensburg, Penn \& Haiden, 1998) have shown that this approach allows for greater statistical control and a transparent interpretation of the contribution of each categorical variable.

On the basis of the descriptive statistics presented thus far, a series of seven stepwise multiple regressions is developed to explain sighted wine quality in the presence of both intrinsic merit and the expert cue. To allow for the analysis of variance across the complete 224-line dataset, all wine tasting data is analysed in its unabridged (and un-averaged) form. 
Models are presented at (1) a general meta-level as well as from the segmented sub-perspectives of gender ((2) male versus (3) female), particular experience bands ((4) novice and (5) expert) and age bands ((6)18-30 years versus (7) older than 30 years).

In the construction of stepwise regression models a critical $t$ score of 1,96 is generally employed. However, with smaller datasets such as the one in this study, the absolute significance of the 1,96 threshold tends to wane, with increasingly higher critical $t$-scores required as the size of data diminishes. Care was taken to ensure that governing $t$ stat thresholds were properly adjusted to account for this dynamic. The results of the seven models developed are depicted in Table IV below.

So as to avoid the dummy trap we specify the following categorical comparators: "Age" (over 35), "Gender" (Female), "Years of drinking wine" (over 35), "drinks per week" (between two and four), and Knowledge of Industry ("three" / intermediate). Coefficients produced in the models depicted should thus be considered relative to these comparators which in turn are represented by the constant term derived in each model.

Table 4: Estimated step-wise regressions explaining sighted wine assessments

\begin{tabular}{lcc}
\hline \multicolumn{1}{c}{ Variable } & Coefficient \\
\hline \multicolumn{1}{c}{ Meta-model: Sighted: Adj $R^{2}: 14,09 \%, F: 13,19(p=0,0000), n=224$, critical t-stat: $2,04}$. \\
Constant: & 1,12 & 2,44 \\
Expert Platter: & 0,51 & 4,31 \\
Years of Drinking: 9 to 35 years: & $-0,44$ & $-3,76$ \\
Blind Rating: & 0,10 & 2,04 \\
\hline
\end{tabular}

\begin{tabular}{lc}
\hline 2. Male model: Sighted: Adj $R^{2}: 18,24 \%, F: 11,45(p=0,0000), n=147$, critical t-stat: $2,08$. \\
Constant: & 0,72 \\
Blind Rating: & 0,21 \\
Expert Platter: & 0,48 \\
Age: 18 to 21 years: & 0,49 \\
\hline
\end{tabular}

\begin{tabular}{lc}
\hline 3. Female model: Sighted: Adj $R^{2}: 16,76 \%, F: 8,65(p=0,0004), n=77$, critical t-stat: $2,20$. \\
Constant: & 0,63 \\
Wine Experience: Novice: & 0,62 \\
Expert Platter: & 0,57 \\
\hline
\end{tabular}

\begin{tabular}{lc}
\hline & \\
\hline 4. Wine Novice model: Sighted: Adj $R^{2}: 21,13 \%, F: 15,87(p=0,0000), n=112$, critical t-stat: $2,12$. & 0,52 \\
Constant: & 0,76 \\
Expert Platter: & $-0,55$ \\
Years of Drinking: 9 to 35 years: & 4,62 \\
\hline & $-3,23$ \\
\hline 5. Wine Expert model: Sighted: Adj $R^{2}: 28,66 \%, F: 14,66(p=0,0005), n=35$, critical t-stat: $2,57$. \\
Constant: & 1,62 \\
Blind Rating: & 0,57 \\
\hline
\end{tabular}

\begin{tabular}{|c|c|c|}
\hline \multicolumn{3}{|c|}{ 6. Age: “Younger than 30" model: Sighted: Adj $R^{2}: 12,11 \%, F: 13,47(p=0,0000), n=182$, critical t-stat: 2,06. } \\
\hline Constant: & 0,65 & 1,24 \\
\hline Expert Platter: & 0,60 & 4,44 \\
\hline Years of Drinking: 0 to 8 years: & 0,37 & 2,70 \\
\hline \multicolumn{3}{|c|}{ 7. Age: “30 or older” model: Sighted: Adj $R^{2}: 22,45 \%, F: 12,87$ ( $\left.p=0,0009\right), n=42$, critical t-stat: 2,45. } \\
\hline Constant: & 3,64 & 23,52 \\
\hline Years of Drinking: 9 to 35 years, & $-0,79$ & $-3,59$ \\
\hline
\end{tabular}

By virtue of the depicted $P$ and $F$ scores we note that all models are statistically significant. In each model the selected critical $t$-stat corresponds with the number of subjects involved (i.e.: total observations $(n)$ divided by seven). Per model, each qualifying candidate variable's $t$-stat is greater than that of the cited critical $t$-stat. However in models $2,3,4$ and 6 , the $t$-stat of the constant is smaller, thus indicating lesser degrees of certainty for the associated dummy comparators. (Critical $t$-stats are sourced from Malhotra, 2007: A7-A9) 


\section{Findings}

\section{The meta model}

As per Table IV, the general regression equation describing the sighted score for each wine, $i$, is laid out below (together with a residual error $(\varepsilon)$ term that obeys the classical assumptions). Relevant $t$ statistics appear beneath in brackets and are significant throughout.

Sighted $_{\mathrm{i}}=1,12+0,51$ Platter $_{\mathrm{i}}-0,44(9-35$ yrs drinking $)+0,10$ Blind $_{\mathrm{i}}$

$(-3,76)$

The model's constant is 1,12 , meaning that if all the independent variables are held at zero, the sighted score is likely to be 1,12 . The relationship between the sighted score and the expert Platter score is described by the coefficient 0,51. Therefore, with all other factors held constant, for every one star increment in Platter, the sighted judgement of a wine is likely to increase by a fraction more than half a star. Thus if we hold constant the intrinsic quality and increase the expert rating from two to four stars, the consequent increase in sighted appreciation will be by more than one full star. At an aggregate level, the mean average sighted score (of 3,21) is appreciably higher than that of the blind score $(2,71)$. Possibly, this is explained by the much higher mean average Platter score (of 3,79).

Platter aside, the model is complexified by the matter of how long one has been drinking wine. From the equation above, we note that those with between nine and 35 years of wine drinking experience (10 out of the sample of 32 subjects) will tend to be more severe in their wine assessments: subtracting some 0,44 stars, ceteris paribus. Critically this factor does not apply to those with less wine experience (zero to eight years of drinking - 19 subjects in all). Thus at this meta-level we can note, already, the generally negative effect that wine-drinking experience has on sighted scores. While more shall be said of this later, it is clear from the model above that this "experience" factor (along with the other inter-correlated factors of age, weekly consumption and relative expertise) will tend to dampen the effect of professional scores like Platter.

The blind-based variable of intrinsic merit only becomes relevant once the expert (Platter) cue and personal experience have been assimilated into the model. (With a $t$ statistic of 2,04 the intrinsic cue is the least significant of the three variables in this meta-model). Reading from equation above, we note that for each "intrinsic" or "blind" star, the sighted score is likely to increase by a mere 0,10 of a star. Remarkably, this effect is but one-fifth that of the effect of the expertise cue (whose coefficient equals 0,51.)

\section{The gender models}

Respectively, models are derived for male and female subjects and reported in Table IV. In both instances, the expert cue is found to be relevant. By virtue of the coefficient assigned to the Platter cue in each equation, $(0,48$ for males $(t=3,33)$, and 0,57 for women $(t=2,85))$ it seems that women appear more affected by the cue. The male-subject model also features the "blind" intrinsic merit variable with a coefficient of $0,21 \quad(t=3,42)$. This coefficient represents less than half the weighting of the
Platter cue $(0,48)$. In the presence of the Platter cue, women in this study appear to be unaffected by the intrinsic merit of the wine. The model for male subjects also suggests that, relative to others in the subset, those between 18 and 21 years of age $(\mathrm{n}=$ eight $)$ tend to over-score their wines by about 0,49 stars $(t=3,01)$. In the female equation, a similar rate of over-scoring $(0,62$ stars, with $t=3,03)$ is noted by those who deem themselves wine "novices".

\section{Wine expertise models}

We sought to model the effect of wine expertise (or the lack thereof) on sighted wine assessments. Accordingly we developed models for those who, with respect to their understanding and appreciation of the wine market, deemed themselves (1) novices (16 subjects), (2) intermediates (11 subjects) or (3) experts (five subjects). No model was possible with respect to intermediates since no statistically significant factors could be located. The novice and expert models appear in Table IV.

With respect to novices, the Platter cue coefficient (of 0,76 , with $t=4,62$ ) is by far the largest of any of the equivalent coefficients developed in this study. (For example, compare this to the meta-model Platter co-efficient of 0,51 , with $t=$ 4,31). Relative to the wider wine-drinking populace, this variance underlines the extent to which younger and less experienced wine drinkers are influenced by such cues. Within the novice model, as with the meta-model, we note once more that those with between 9 and 35 years of wine drinking (four out of the 16 in this sub-sample) will tend to be more severe in their wine assessments: this time subtracting some 0,55 stars, ceteris paribus $(t=-3,23)$.

By comparison to the novice model, the relative expert model contains no reference to the Platter cue, and is driven, solely, by intrinsic merit. Here, the blind coefficient is $0,57(t=3,83)$; a figure massive by comparison to the meta-model blind coefficient of $0,10(t=2,04)$. This said, while the derived model is statistically significant $(\mathrm{F}=$ $14,66 ; p=0,0005)$, a sample of seven wines tasted by a mere five self-proclaimed experts is too small to draw inference on the ability of the wine-tasting profession to remain unbiased in the presence of extrinsic cues. The study by Priilaid (2007) appears to demonstrate that professional wine tasters are influenced by the prevalence of extrinsic cues - and thus it seems we have two conflicting views. Reportage of a statistically robust experiment akin to this study but comprising only professional tasters would serve to settle the issue one way or the other, as would fMRI-type studies (as per Plassmann et al., 2008) employing sommeliers and the like as subjects.

\section{Age models}

We investigated whether certain age segments responded differently to the expertise cue. As per Table IV, two models were developed: one for those younger than 30 years; the other for those 30 years and older.

The young adult model - those younger than 30 years produced a two-factor model. In all, 26 subjects qualified under this segmentation. The first of these factors is the expert Platter cue, with a coefficient of $0,60(t=4,44)$. This is the second highest of the expert cue coefficients; and, as 
with the novice model, confirms the efficacy of the expert cue effect on the younger, less-experienced demographic.

For subjects who have been drinking wine for fewer than eight years this cue-effect is heightened. 19 out of the 26 people within this sub-sample qualified under this category. Ceteris paribus, the model suggests that these subjects will add an additional 0,37 stars to their sighted rating $(t=2,70)$. As with the novice model, blind ratings do not appear to have any influence on the tasting assessments of young adults.

Finally a one-factor model was developed for those subjects 30 years or older. In all, six subjects qualified here - the only statistically significant variable being wine drinking experience: 9 to 35 years. Half the sample qualified under this specification, the remaining half presenting with over 36 years of wine drinking experience. Those with less experience tended to subtract 0,79 stars from their sighted assessment $(t=-3,79)$. Unlike the wine "expert" model, blind ratings were not deemed significant. Further comparison of these two models suggests that the key factor driving the efficacy of intrinsic merit and the expert cue effect is not so much that of age but rather how long one has been consuming wine. Moreover, the rate of consumption as measured by the weekly intake of wine does not feature in any of the models produced; possibly suggesting that this factor is supervened by the duration rather than intensity of wine-drinking experience.

\section{Conclusion}

Through the deployment of blind and sighted versions of hedonic quality, this paper considers expert ratings as placebo effects and by so doing observes the extent to which these particular cues mediate the sighted appreciation of a wine when controlling for intrinsic merit. In the absence of contending cues such as brand, price and area-of-origin, the reported experiment required no further cue-controls. The placebo-driven specification is consistent with much of the wine-marketing literature (inter-alia) that seeks to interpret extrinsic cues as non-medical placebos and which to date has identified the price and terroir-cue as moderators of a wine's intrinsic merit (see Plassmann et al., 2008; Priilaid, 2007).

The findings of this study reveal the extent to which Platter's expert rating cues consistently mediate the sighted appreciation of wine, this particularly within the younger, less experienced demographic. Here cues appear to serve a heuristic function, assisting in a process of judgement where more enabling cues are absent.

When attempting to explain sighted assessments at the metalevel of all subjects tested, an examination of the model's driving coefficients suggests that the cue of expert ratings (coefficient $=0,51$ ) appears to operate at five times the strength of the original intrinsic rating (coefficient $=0,10$ ). In extreme cases, as in the instance of wine novices who have little or no experience in wine appreciation nor the attendant skills of wine merit calibration, the authority of the expert cue increases a further 50 percent (coefficient $=$ 0,76 ), while the influence of intrinsic merit (as proxied by the original blind tasting) falls away completely (coefficient
$=0)$. The situation reverses with self-confessed wine experts. The reported blind rating coefficient of these subjects increases almost six-fold from 0,10 to a remarkable 0,57 . In contradistinction, the effect of the expert cue is reduced to nothing (coefficient $=0$ ).

For wine marketers, such findings suggest that the promotion of this extrinsic cue be targeted more specifically at wine "novices" rather than at the "general" wine-drinking public. The consequent narrowing of marketing focus would in turn imply a more judicious and effective employment of promotional and general advertising budgets. We speculate that this finding applies not merely to the expert cue but to those others (price and area-oforigin) already identified in the literature.

While this might well be the case, as yet we do not know how expert quality ratings would operate in tandem with, for example, the price cue. Which would be stronger; why; and under what conditions? Further studies employing fMRI styled assessments so as to observe the effect of the simultaneous combination of extrinsic cues on ordinary subjects might resolve some of these questions, though statistically, the use of brain scanning research to test for more than one factor might prove difficult to control. Certainly the simultaneous invocation of sighted and blind scores as per publications like Platter and WINE magazine (respectively) are of little use here since the professional tasting "subjects" in both respects cannot be considered members of the ordinary wine-drinking public.

This aside, the outcome of this particular study serves to forge a critical link in the causal chain of wine-placebo research to date. To elaborate: while studies cited in this study have shown that extrinsic cues like price and terroir have a marked effect on the sighted ratings of Platter, to date it has remained uncertain whether, as cues, these professional ratings serve in turn to influence the winedrinking public in their own sighted assessments of wine. From the study at hand, we now know that they do. Further neurological enquiry will serve to clarify the extent to which such cues remain efficacious and why.

\section{References}

Berns, G.S. 2005. 'Price, placebo, and the brain', Journal of Marketing Research, 42 (November): 399-400.

Boom, C. (Ed.). 2006. SA Wine Industry Directory 2006/7. $8^{\text {th }}$ Edition. Cape Town: Wineland Publications.

Borsook, D. \& Becerra, L. 2005. 'Placebo: From pain and analgesia to preferences and products', Journal of Marketing Research, 42 (November): 394-398.

Darlington, D. 2005. 'The chemistry of a $90^{+}$wine', The New York Times. [online] URL:

http://www nytimes.com/2005/08/07/magazine/07ENOLOG I.html?_r=1. Accessed 20 July 2009.

Irmak, C., Block, L.G. \& Fitzsimons, G.J. 2005. 'The placebo effect in marketing: Sometimes you just have to want it to work', Journal of Marketing Research, 42 (November): 406-409. 
Malhotra, N. K. 2007. Marketing research: An applied orientation. $5^{\text {th }}$ Edition. Upper Saddle River, New Jersey: Pearson Education International.

Montague, R. 2006. Why choose this book? How we make decisions. New York: Dutton Press.

Plassmann, H., O’Doherty, J., Shiv, B. \& Rangel, A. 2008. 'Marketing actions can modulate neural representations of experienced pleasantness', Proceedings of the National Academy of Sciences, 105(3): 1050-1054.

Priilaid, D. 2007. 'The placebo of place: Terroir effects in the blind and sighted quality assessments of South African varietal wines, Journal of Wine Research, 18(2): 87-105.

Priilaid, D. \& Van Rensburg, P. 2006. 'Non-linearity in the hedonic pricing of South African red wines', International Journal of Wine Marketing, 18(3): 166-182.

Rao, R.R. 2005. 'The quality of price as a quality cue', Journal of Marketing Research, 42 (November): 401-405.

Robinson, J. 2008. 'South African stars, served on a 'Platter', Financial Times. [online] URL:

http://www.ft.com/cms/s/2/2ff788a2-fc5a-11dc-9229-

$000077 \mathrm{~b} 07658 \mathrm{html}$ ?nclick_check=1. Accessed 20 July 2009.

Seghieri, C., Casini, L. \& Torrisi, F. 2007. 'The wine consumer's behaviour in selected stores of Italian major retailing chains', International Journal of Wine Business Research, 19(2): 139-151.

Shiv, B., Carmon, Z. \& Ariely, D. 2005. 'Placebo effects of marketing actions: Consumers may get what they pay for', Journal of Marketing Research, 42 (November): 383-393.

Spawton, T. 1991. 'Marketing and planning for the wine industry', European Journal of Marketing, 24(3): 6-48.

Taplin, I.M. 2006. 'Competitive pressures and strategic repositioning in the Californian premium wine industry', International Journal of Wine Marketing, 18(1): 61-70.

Thrane, C. 2004. 'In defence of the price hedonic model in wine research', Journal of Wine Research, 15: 123-134.

Van Rensburg, P., Penn, G. \& Haiden, M. 1998. 'A note on the effect of secondary accounting study on university accounting performance', SA Journal of Accounting Research, 12(1): 93-98. 